orbitale of the ethmoid is reduced". In the orang and the gibbon a large planum orbitale articulates in front with the lacrimal, as in man. The figure we give of the orbital wall in Plesianthropus shows a condition almost exactly as in man.

We are here not at present concerned with the question of whether man and the Australopithecinæ have arisen from an early anthropoid, or a preanthropoid, or an Old World monkey or a tarsioid; but we think the evidence afforded by this new skull of Plesianthropus shows that the Australopithecinæ and man are very closely allied, and that these smallbrained man-like beings were very nearly human.

$$
\text { R. BRoOM }
$$

J. T. ROBINSON

Transvaal Museum, Pretoria. May 26.

\section{Conversion of Carbon Dioxide to Acetylene on a Micro Scale}

As a preliminary to future attempts to synthesize, on a very small scale, biologically important compounds containing radioactive carbons $\mathrm{C}^{14}$ or $\mathrm{C}^{11}$, we have developed a technique for the conversion of small quantities of carbon dioxide to acetylene. Both carbon isotopes ${ }^{1,2}$ are most conveniently prepared in the chemical form of carbon dioxide, but acetylene is a better starting substance for a number of syntheses. In our experiments, pure barium metal was heated in a stainless steel vacuum furnace of special design in the presence of carbon dioxide, which was absorbed with the formation of barium carbide.

Quantities of ordinary inactive carbon dioxide varying from 50 to 500 microlitres at N.x.P. were measured in a McLeod gauge and transferred through a high-vacuum apparatus to the stainless steel furnace containing about $40 \mathrm{mgm}$. of barium metal which had been scraped as clean as possible before weighing. The furnace was heated to $600^{\circ} \mathrm{C}$. for 5-10 min. and all the carbon dioxide disappeared. The furnace was cooled and its contents dissolved in water. The gas mixture obtained was found to consist (apart from water vapour and hydrogen) of acetylene, ammonia formed from barium nitride and a trace of ethylene which never exceeded 2 per cent of the total $\mathrm{C}_{2}$ hydrocarbons.

Acetylene was separated by passing the mixture through a rough drying trap at $-78^{\circ} \mathrm{C}$. and then adsorbing ammonia, water vapour, acetylene and the trace of ethylene from the hydrogen stream on to active charcoal at $-78^{\circ} \mathrm{C}$, , the hydrogen being pumped away. The temperature of the charcoal was raised to $0^{\circ} \mathrm{C}$., when an appreciable proportion of the acetylene (and ethylene) was desorbed : the acetylene was finally condensed into a trap connected with the McLeod gauge. No ammonia or water vapour is desorbed at this temperature during the ten minutes necessary for practically all the acetylene to be recovered.

The results were as follows:

\begin{tabular}{|c|c|c|c|c|}
\hline $\begin{array}{l}\text { Expt. } \\
\text { No. }\end{array}$ & $\begin{array}{c}\text { Carbon dioxide } \\
\text { used } \\
\text { ( } \mu 1 . \text { at N.T.P.) }\end{array}$ & $\begin{array}{c}\text { Acetylene } \\
(+ \text { ethylene }) \text { found } \\
(\mu 1 \text {. at N.T.P. })\end{array}$ & $\begin{array}{l}\text { Acetylene blank } \\
(\mu \mathrm{l} \text {. at N.T.P. }\end{array}$ & $\underset{\%}{\text { Yield }}$ \\
\hline $\begin{array}{r}21 \\
22 \\
23 \\
24 \\
* 25 \\
27 \\
28 \\
* 29\end{array}$ & $\begin{array}{r}335 \\
273 \\
300 \\
305 \\
62 \\
558 \\
566 \\
50\end{array}$ & $\begin{array}{c}178 \\
133 \\
140 \\
140 \\
25 \cdot 5 \\
265 \\
260 \\
21 \cdot 5\end{array}$ & $\begin{array}{l}14 \\
12 \\
3 \\
3 \\
1 \cdot 1 \\
3 \\
2 \\
2 \cdot 8\end{array}$ & $\begin{array}{l}98 \\
89 \\
91 \\
90 \\
79 \\
94 \\
91 \\
79\end{array}$ \\
\hline
\end{tabular}

Stainless steel was found to be the most satis. factory furnace material tried. From mild steel relatively large amounts of acetylene were produced in blank experiments, and a fused silica envelope fitted with a nickel thimble was found, after it had been used with calcium and barium metals, to absorb carbon dioxide when hot even when no calcium or barium was present. In carrying out the absorption of carbon dioxide by barium metal in the stainless steel furnace it was found that when the pressure at which the gas was admitted was less than about $10^{-1} \mathrm{~mm}$. of mercury, the yield of acetylene was variable and only about 45 per cent. Good yields were obtained when the carbon dioxide at its full pressure was admitted to the furnace before raising the temperature above $400^{\circ} \mathrm{C}$. It was further found that if acetylene, ammonia and water are condensed together in the presence of mercury, acetylene is lost very rapidly on warming up the mixture. This may be due to the formation of mercury acetylide. Losses due to all the above causes are avoided by following a standard procedure.

For the identification of all the gases involved in these experiments, physical and chemical methods were applied. Vapour pressures at low temperatures were measured, and individual gases were absorbed from mixtures with standard reagents. Acetylene in particular was absorbed in a paste of cuprous chloride and caustic potash solution with the formation of red copper acetylide.

The conversion of carbon dioxide to acetylene can be carried out in about half an hour. This may make possible the synthesis of many compounds containing $\mathrm{C}^{11}$ of half-life $20.5 \mathrm{~min}$.

Full experimental details of this work will be published elsewhere.

We wish to thank Prof. W. H. Linnell for his interest and support, many others for helpful conversations, the Research Laboratories of the General Electric Co., Ltd., for a specimen of very pure barium metal, and to acknowledge generous grants from the Therapeutic Research Corporation, the Royal Society, the Medical Research Council and the Central Research Fund of the University of London. One of us (R. G.) is a Keddey Fletcher-Warr student of the University of London.

Wrlliam J. Arrol

RAYMOND GLASCOCK

College of the Pharmaceutical Society,

University of London,

17 Bloomsbury Square,

London, W.C.1.

March 26.

1 Ruben and Kamen, Phy8. Rev., 59, 349 (1941).

${ }^{2}$ Yost, Ridenour and Shinohara, J. Chem. Phys., 3, 133 (1933).

\section{A New Indicator for Iodometric Analysis}

IT is well known to analysts that starch is very far from being an ideal indicator for iodine, and the disadvantages from which it suffers are not all avoided by the use of an acid-solubilized starch. It will be agreed that the chief disadvantages attending the use of starch are: (1) the insolubility of starch in cold water ; (ii) the instability of starch dispersions in water, in consequence of which a stock solution soon deposits a flocculent precipitate of retrograded starch; (iii) that starch gives with iodine a waterinsoluble complex, the formation of which precludes the addition of the indicator early in the titration; 